\title{
Comparison between Mexican and International Medical Graduates' scores in the ENARM Competing for Clinical Specialities in Mexico during 2012-2019: Data Visualization, Trends and Forecasting Analyses
}

\author{
Alexela-Nerey Mendoza-Aguilar ${ }^{1}$, Aime Cedillo-Pozos ${ }^{1}$ and Ernesto Roldan-Valadez ${ }^{1,2,}$ \\ ${ }^{1}$ Directorate of Research, Hospital General de Mexico "Dr Eduardo Liceaga”, Mexico City, Mexico \\ ${ }^{2}$ I.M. Sechenov First Moscow State Medical University (Sechenov University), Department of Radiology, \\ Moscow, Russia
}

\begin{abstract}
Objectives: Because there is heterogeneity in the ENARM scores obtained between Mexicans and International medical graduates (IMG) in the eight clinical specialities with direct-entry (Anesthesiology, and Emergency Medicine. Geriatrics, Internal Medicine, Medical Genetics, Pediatrics, Pneumology, Psychiatry), we aimed to evaluate those scores. We hypothesized that Mexican test-takers achieve higher scores than IMG with significant growth trends in their exam scores.

Methods: This study was cross-sectional, used historical data from the annual public report of the ENARM for eight years (2012 to 2019). We compare the minimum (MinSco) and maximum (MaxSco) scores of each speciality using ANOVA. Mexican versus IMG scores were evaluated with an independent student t-test, trends with Spearman's correlation coefficient, and a 5-years forecasting trend.

Results: There was a significant difference among the MinSco for five surgical specialities; $F(7,115)=26.611, p=<$ .001; the global mean of MinSco was 69.133; specialities above this mean were Internal Medicine, Anesthesiology, Pediatrics, and Pneumology. The global mean for MaxSco was 79.422; five specialities were above: Internal Medicine, Pneumology, Geriatrics, Psychiatry, and Medical Genetics. We did not find a significant difference in the MinSco between Mexicans and IMG, but a significant difference was found in the MaxSco between both groups.
\end{abstract}

Conclusions: ENARM represents a market of high-performance test-takers across the clinical specialities. Mexicans and IMG achieved similar entrance scores, but Mexicans showed a higher MaxSco over IMG in all clinical specialities.

Keywords: ENARM, internship and residency, medical education, medicine speciality.

\section{INTRODUCTION}

\section{Education of Graduated Doctors}

The residence is a critical step in graduated doctors' education since $90 \%$ aspire to a postgraduate or medical speciality [1]. In the USA, up to $88 \%$ of general practitioners will eventually study a medical speciality; this percentage decrease to $35 \%$ in Mexico [2]. The score that a general practitioner (GP) obtains in the National Evaluation for Medical Residency Applicants (ENARM, Examen Nacional de Aspirantes a Residencias Medicas) is the entrance door to a specialization course endorsed by a Mexican University $[3,4]$.

\section{Logistics of the ENARM}

The ENARM is a one-step only exam that uses multiple-choice questions and computerized patient cases to assess examinees' knowledge related to

*Address correspondence to this author at the Directorate of Research, Hospital General de Mexico, Dr. Balmis 148, Colonia Doctores, Delegacion Cuauhtemoc, 06726 Ciudad de Mexico, Mexico; Tel: +52155-2789-2000 ext. 1149; E-mail: ernest.roldan@usa.net foundational science concepts applicable to medical and scientific theories to clinical medicine; details concerning the logistics' of the exam has been published previously $[5,6]$.

In Mexico, the Interinstitutional Commission issued the reports for Human Resources Training for Health (CIFRHS, Comisión Interinstitucional para la Formación de Recursos Humanos para la Salud) is an inter-institutional, consultation, advisory and technical support organization of the Ministry of Public Education and the Ministry of Health [7]; it considers 27 medical specialities with a direct entry [8]. For the Mexican educational institutions, the ENARM scores and the percentages of their graduates' selection are indicators of efficiency and reason of prestige and even of propaganda among the aspirants to study medicine [9].

\section{Conceptual Framework}

Conceptual frameworks play an important, essential role in identifying the nature of education problems and in formulating solutions or designing studies [10]. Each year the number of applicants to the Mexican assessment known as ENARM increase; in 2019, there 
were more than 57,000 applicants, and only 9,668 Mexican and international medical graduates (IMG) were selected [11]. Several problems about the ENARM have been addressed in recent publications, for example, the number of Mexican test-takers and accepted GPs belonging to each Mexican medical school registered in the ENARM [3]; the logistics and transparency of the ENARM exam [5]; the performance of private versus public schools using a summary measures method, exploring significant differences in the performance based on geographic regions and socioeconomic level of the Mexican states to which each school belongs [3, 12]; and the assessment of the assumption of equity in the ENARM [6].

There is an educational problem in Mexico related to the applicant's heterogenous ENARM scores to clinical specialities $[1,13,14]$. We do not know the eight clinical specialities' academic performance with a direct entry: Anesthesiology, Emergency Medicine, Geriatrics, Internal Medicine, Medical Genetics, Pediatrics, Pneumology, and Psychiatry [14].

We aimed to assess these eight direct-entry clinical specialities' performance and compare the scores of Mexican versus IMG in each speciality; we also included a trend analysis over eight years (2012-2019). We hypothesized that Mexican test-takers achieve higher scores than IMG with significant growth trends in their exam scores.

\section{MATERIALS AND METHODS}

\section{Study Design and Data Acquisition}

This study was cross-sectional and used historical data that did not require approval by an Institutional Review Board. We based our analyses on the annual public report of the ENARM for eight years from 2012 to 2019 issued by the CIFRHS. The reports contained quantitative information on each medical speciality's academic performance from graduate physicians who took the ENARM; these reports are freely available as PDF files at the CIFRHS website [11]. Original data are included as an online-only supplementary file.

\section{Logistics of ENARM and Assessed Variables}

Five test forms are created each year, each comprising 450 multiple-choice single-best answer items; no item is used in more than one test form. All test forms contain the same number of items per area of knowledge (speciality/subspecialty), with an approximate item distribution of $37.5 \%$ internal medicine, $25 \%$ paediatrics, $22 \%$ gynaecologyobstetrics, and $15 \%$ surgery. Applicants for each speciality are ranked from highest to lowest according to their total ENARM score. Ranked applicants receive a 'pass' certificate until the quota is met according to that speciality's available positions [6].

For each year (2012-2019), we recorded the minimum and maximum scores (calculated by dividing the absolute number of correct answers by the total number of items) clustered by nationality (Mexican or IMG) and chosen speciality (8 direct-entry specialities) that coincidentally appear in the annual CIFRHS report.

\section{Statistical Analysis and Data Visualization Techniques}

\section{Part I, Comparison of the Minimum and Maximum Scores among Surgical Specialities}

In the first part of our analysis, we compare the minimum (MinSco) and maximum (MaxSco) scores of the eight direct-entry clinical specialities evaluated by the ENARM (Anesthesiology, Emergency Medicine, Geriatrics, Internal Medicine, Medical Genetics, Pediatrics, Pneumology, Psychiatry); the KolmogorovSmirnoff and Shapiro-Wilk tests showed a nonsignificant $p$-value for each speciality, which indicated a normal distribution of data in both variables (MinSco and MaxSco). Then, we performed a one-way ANOVA to reveal the differences in the scores achieved by each speciality; variables were tested for homogeneity of variance, and posthoc tests used the LSD (least significant difference) method. To test the assumption that MinSco and MaxSco increase every year, we assessed a significant linear trend for the scores to increase across the specialities. For this assessment, we use the Polynomial option (in the ANOVA menu of SPSS); it chose the Degree: Linear (default) option in its Contrast box. Detailed descriptions of the ANOVA test in clinical settings have been previously published by our group $[15,16]$. Descriptive statistics were used for each variable and $95 \%$ confidence intervals (C.I.) [17]. The effect size assessment (proportion of the variance in the dependent variable that the independent variable can explain) of each result was obtained using the Partial Eta Squared $\left(\eta^{2}\right)$. Partial eta squared was defined as the ratio of variance associated with an effect, plus that effect and its associated error variance.

$$
\eta^{2}=S S_{\text {effect }} / S_{\text {effect }}+S S_{\text {error }} \text {, where: }
$$

$\mathrm{SS}_{\text {effect }}$ is the sums of squares for the effect the researcher is studying. 
The values of $\eta^{2}$ were classified in three groups 0.01 to $0.06=$ small effect, 0.06 to $0.14=$ moderate impact, and $>0.14=$ substantial effect [18].

To visualize the results, we use graph lines showing the evolution of MinSco and MaxSco every year for each speciality. We also drew bar graphs with the global means indicating those specialities whose mean were above or below a global mean for all specialities.

Part II, Comparison of the Minimum and Maximum Scores between Mexican and IMG, Correlations, Trend Lines and Forecasting Analyses

For the second part of our analysis, we looked for significant differences between Mexican and IMG in their scores by independently analyzing each speciality.

The Comparison of means was made using the independent T-test. The Pearson's correlation coefficient helped us to reveal direction trends: positive for increasing scores $(\uparrow)$ with every year (2012 to 2019) or negative for decreasing scores $(\downarrow)$.

\section{Linear Trend Lines}

We calculated the trend of the MinSco and MaxSco every year for each speciality,

Linear trend lines are lines of best fit used to estimate a linear relationship in the data. They have the following form:

$$
\mathrm{Y}=\beta_{0}+\beta_{1} X
$$

where $Y$ is the dependent variable, and $X$ is the independent variable that affects it. They represent the simplest trend line model in that they estimate a relationship that is increasing or decreasing at a steady rate $\beta_{1}$ and are therefore best used when the trend of the data resembles a linear pattern. We reported the $p$ values and the R-squared (a measure of how well the trend line fits the data). The latter considered the best indicator of model performance.

\section{Forecasting Analyses}

We forecasted our quantitative time-series data using a triple exponential smoothing method, which is also called Holt-Winters exponential smoothing [19, 20]. It was applied using CTableau software. This method is used for forecasting the univariate time series when the data might have both linear trend and seasonal pattern. In Holt-Winters exponential smoothing, recent observations are given relatively more weight than older observations; it is suitable for short-term forecasting and uses the maximum likelihood function for estimating parameters [21]. We calculated models that captured the evolving trend or seasonality of the data and extrapolated them into the future five-year period with $95 \%$ confidence prediction intervals.

The triple exponential smoothing formulas are given by:

$$
\begin{aligned}
& s_{0}=x_{0} \\
& s_{t}=\alpha \frac{x_{t}}{c_{t}-L}+(1+\alpha)\left(s_{t-1}+b_{t-1}\right) \\
& b_{t}=\beta\left(s_{t}-s_{t-1}\right)+(1-\beta) b_{t-1} \\
& c_{t}=\gamma \frac{x_{t}}{s_{t}}+(1-\gamma) c_{t}-L
\end{aligned}
$$

where,

st $=$ smoothed statistic, it is the simple weighted average of current observation xt

st- $1=$ previous smoothed statistic

$\alpha=$ smoothing factor of data; $0<\alpha<1$

$\mathrm{t}=$ time period

$\mathrm{bt}=$ best estimate of a trend at time $\mathrm{t}$

$\beta=$ trend smoothing factor $0<\beta<1$

$\mathrm{ct}=$ sequence of seasonal correction factor at time $\mathrm{t}$

$Y=$ seasonal change smoothing factor; $0<y<1$

The model used to generate the forecast had three components: Level, Trend, and Season. The value for each component might be one of the following:

1. None: The component is not present in the model.

2. Additive: The component is present and is added to the other components to create the overall forecast value.

3. Multiplicative: The component is present and is multiplied by the other components to create the overall forecast value.

The QUALITY OF THE MODEL was evaluated with five statistical values: 
RMSE: Root mean squared error.

MAE: Mean absolute error.

MASE: Mean absolute scaled error.

MAPE: Mean absolute percentage error.

AIC: Akaike information criterion.

The smoothing coefficients were optimized to weigh more recent data values over older ones, such that within-sample one-step-ahead forecast errors were minimized.

Alpha is the level smoothing coefficient,

Beta is the trend smoothing coefficient, and

Gamma is the seasonal smoothing coefficient.

The closer a smoothing coefficient was to 1.00 , the less smoothing was performed, allowing for rapid component changes and heavy reliance on recent data. The closer a smoothing coefficient was to 0.00 , the more smoothing was performed, allowing for gradual component changes and less reliance on recent data [22].

The forecasting method calculated a 5-years trend in the MinSco and MaxSco of each speciality; we detected a crossing point between Mexican and IMG for each medical speciality.

We used our previously calculated global means for the MinSco and MaxSco to group the Mexican and IMG in specialities that lay above or below each speciality's mean.

Score comparisons were performed using the IBM ${ }^{8}$ SPSS ${ }^{\circledR}$ Statistics software (version 26.0.0.1 IBM Corporation; Armonk, NY, USA). Data visualization of the scores, trends, and forecasting analyses were performed using (CTableau software (version 2019.1.3, Seattle, Washington, USA). Statistical significance considered a $p$-value $<0.05$ (two-tailed).

\section{RESULTS}

\section{Scores Included in the Analysis}

For each score (MinSco and MaxSco), we evaluated 128 measures, 16 for each speciality (8 scores for Mexicans and 8 for IMG for the years 2012 to 2019), with a total of 256 measures included.
However, from the 256 total number of scores, we substracted 24 scores corresponding to some years in which some specialities did not have test-takers; then, a total of 232 scores were included in the analysis.

\section{Grouping of Specialities above or below a Global Mean}

We calculated a MinSco global mean of 69.133. Specialities above this mean were Internal Medicine, Anesthesiology, Pediatrics, and Pneumology. Specialities below the mean corresponded to Psychiatry, Geriatrics, Medical Genetics, and Emergency Medicine.

The global mean for the MaxSco was 79.422, and five specialities were above this mark: Internal Medicine, Pneumology, Geriatrics, Psychiatry, and Medical Genetics. The other four specialities below the global mean were Pediatrics, Anesthesiology, and Emergency Medicine. Figures $\mathbf{1 A}$ and $\mathbf{B}$ show the scores above or below the global mean for surgical specialities.

\section{Comparison of Minimum and Maximum Scores Achieved by Surgical Specialities}

The one-way ANOVA depicted a significant difference among the minimum scores achieved by the eight clinical specialties; $F(7,115)=26.611, p=<$ .001 ; the $\eta^{2}=0.632$ indicated a great effect size. Posthoc tests showed significant differences between each surgical speciality (bonferronni adjusted p-value = .006). Only two pairs of speciality-comparisons were non-significant:

Anesthesiology vs Medical Genetics ( $p=0.010)$, and Anesthesiology vs Pediatrics $(p=0.039)$. There was a significant linear trend for the increasing scores with every year $F(7,115)=4.167, p=<.044$; the $\eta^{2}=$ 0.033 indicated a small effect size.

We also found a significant ANOVA test in the Comparison of the MaxSco between surgical specialities, $F(7,115)=5.561, p<0.001$, which pointed a difference in the MaxSco among the eight specialities; the $\eta^{2}=0.264$ indicated a great effect size . Post-hoc tests showed significant differences between seven pairs of specialty: Anesthesiology vs Emergency Medicine $(p=0.001)$, Anesthesiology vs Medical Genetics ( $p=0.003)$, Emergency Medicine vs Internal Medicine $(p<.001)$, Emergency Medicine vs Pediatrics $(p=0.003)$, Geriatrics vs Internal Medicine $(p<.001)$, Internal Medicine vs Medical Genetics ( $p<.001)$, 

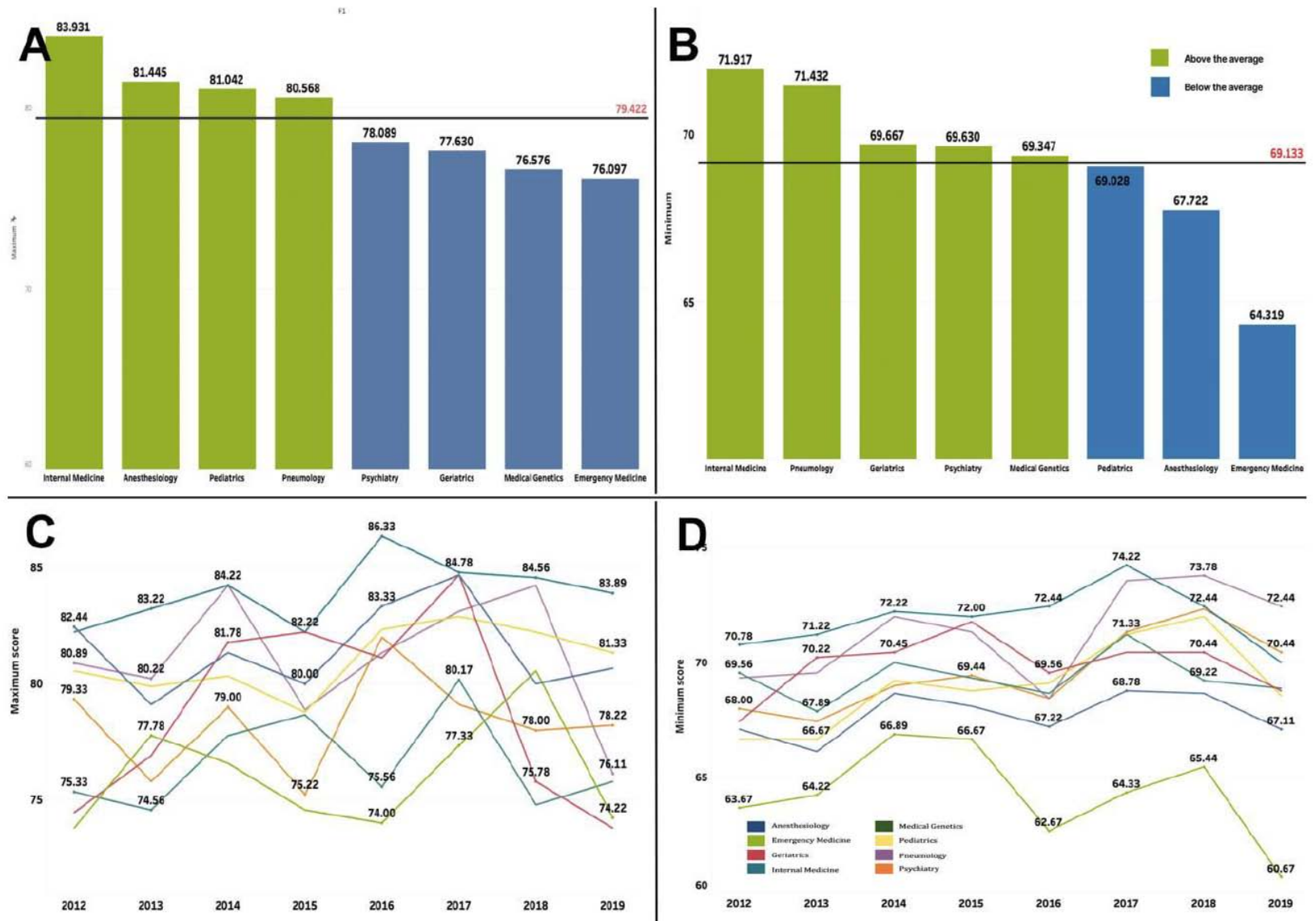

D
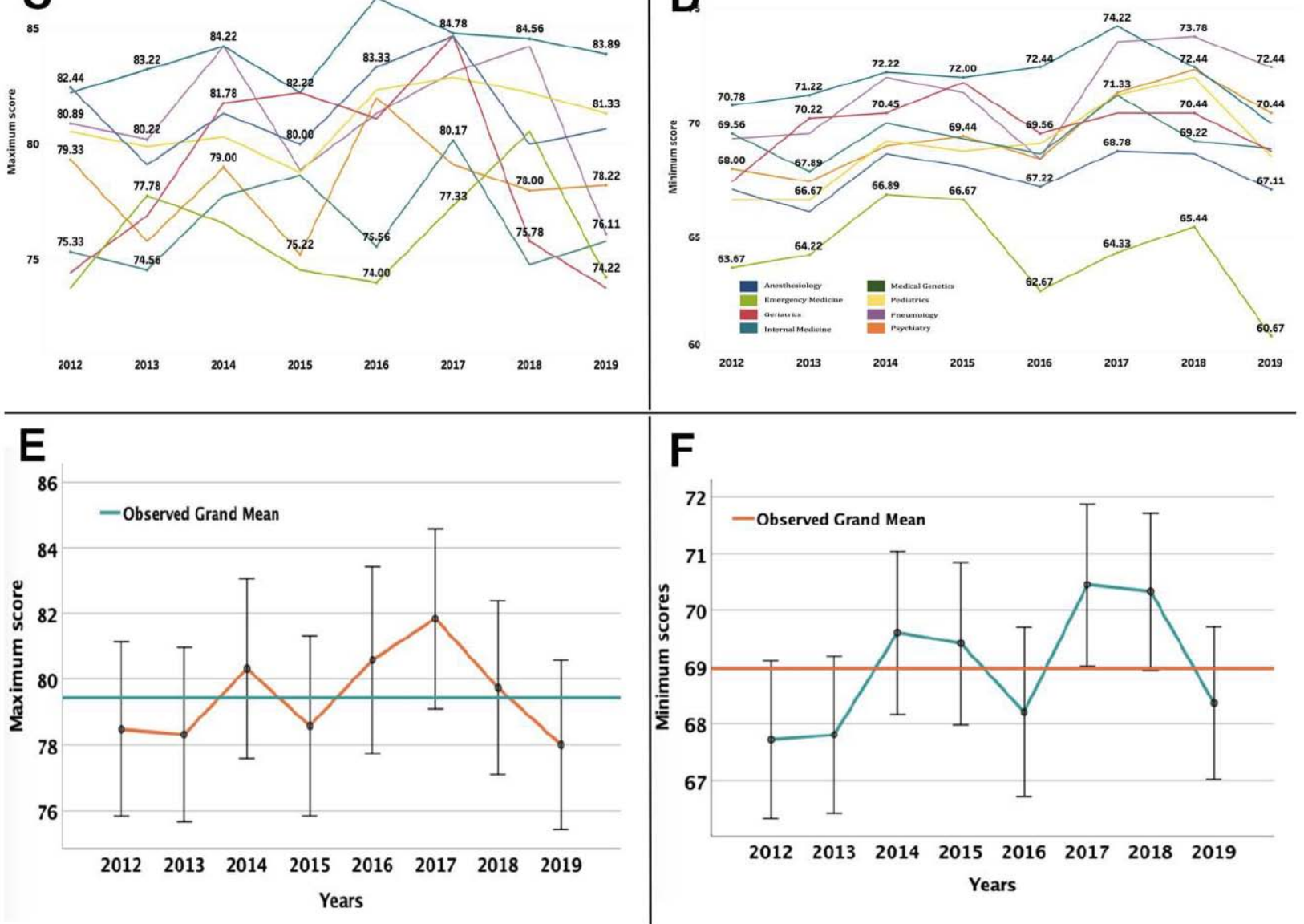

$\mathbf{F}$

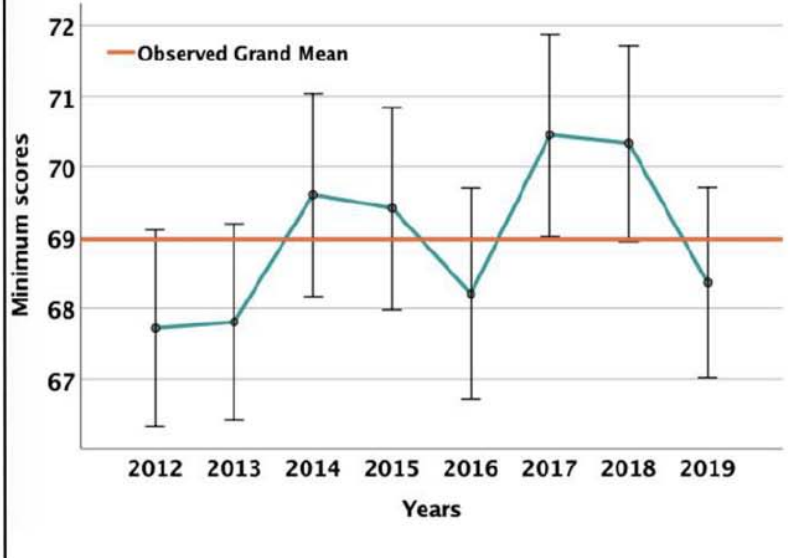

Figure 1: A-B, Scores above or below the global mean for surgical specialities. C-D, mean Comparison of surgical specialities showing the trend by year. E-F, global trend of the MinSco and MaxSco for eight years (2012 to 2019).

Internal Medicine vs Psychiatry $(\mathrm{p}=.001)$. The test for a linear trend of the MaxSco with every year did not show significance $F(7,115)=.360, p=0.550$; with a small effect size, $\eta^{2}=0.003$. Figures $1 C$ and $\mathbf{D}$ show a comparison of the means of each clinical speciality by year. Figures $1 E$ and $F$ depict the global performance of the MinSco and MaxSco for eight years (2012 to 2019).
Table 1 depicts the means, standard deviation, standard error, and $95 \% \mathrm{Cl}$ for the MinSco and MaxSco scores in each speciality.

\section{Comparison of Minimum and Maximum Scores between Mexicans and IMG in each Clinical Speciality}

For the MinSco, it was very interesting to notice that the IMG got higher scores for all clinical specialities. 
Table 1: Means, Standard Deviation, Standard Error, and 95\% Confidence Intervals (C.I.) for the Minimum and Maximum Scores in each Speciality

\begin{tabular}{|c|c|c|c|c|c|c|c|}
\hline \multicolumn{8}{|c|}{ Minimum scores } \\
\hline \multirow[t]{2}{*}{ Specialities } & \multirow[t]{2}{*}{ Mean } & \multirow[t]{2}{*}{ Std. Deviation } & \multirow[t]{2}{*}{ Std. Error } & \multicolumn{2}{|c|}{$95 \%$ Confidence Interval for Mean } & \multirow[t]{2}{*}{ Minimum } & \multirow[t]{2}{*}{ Maximum } \\
\hline & & & & Lower Bound & Upper Bound & & \\
\hline Anesthesiology & 67.722 & 1.923 & 0.481 & 66.698 & 68.747 & 63.778 & 70.666 \\
\hline Emergency medicine & 64.319 & 2.155 & 0.539 & 63.171 & 65.467 & 60.000 & 68.000 \\
\hline Geriatrics & 69.667 & 1.482 & 0.428 & 68.725 & 70.608 & 67.111 & 71.778 \\
\hline Internal medicine & 71.917 & 1.254 & 0.313 & 71.248 & 72.585 & 70.000 & 74.444 \\
\hline Medical Genetics & 69.347 & 1.332 & 0.333 & 68.637 & 70.057 & 67.556 & 72.889 \\
\hline Pediatrics & 69.028 & 1.855 & 0.464 & 68.039 & 70.016 & 66.445 & 72.000 \\
\hline Pneumology & 71.432 & 2.109 & 0.703 & 69.811 & 73.053 & 68.444 & 74.222 \\
\hline Psychiatry & 69.630 & 1.874 & 0.484 & 68.592 & 70.667 & 67.111 & 73.778 \\
\hline \multicolumn{8}{|c|}{ Maximum scores } \\
\hline Anesthesiology & 81.445 & 3.126 & 0.781 & 79.779 & 83.110 & 75.111 & 86.667 \\
\hline Emergency medicine & 76.097 & 4.916 & 1.229 & 73.478 & 78.717 & 68.889 & 83.111 \\
\hline Geriatrics & 77.630 & 6.023 & 1.739 & 73.803 & 81.456 & 67.778 & 84.667 \\
\hline Internal medicine & 83.931 & 3.575 & 0.894 & 82.026 & 85.835 & 77.777 & 89.333 \\
\hline Medical Genetics & 76.576 & 5.070 & 1.268 & 73.875 & 79.278 & 69.779 & 84.444 \\
\hline Pediatrics & 81.042 & 4.748 & 1.187 & 78.511 & 83.572 & 73.556 & 89.111 \\
\hline Pneumology & 80.568 & 3.234 & 1.078 & 78.082 & 83.054 & 74.222 & 84.223 \\
\hline Psychiatry & 78.089 & 5.049 & 1.304 & 75.293 & 80.885 & 69.555 & 86.000 \\
\hline
\end{tabular}

However, Anesthesiology was the only speciality with a significant difference between Mexicans and IMG. For Mexicans, the highest score was Internal Medicine, but for the IMG was Pneumology.

For the MaxSco, we observed exactly the reverse trend, Mexicans got the higher scores in all the specialities, and the differences between scores were all statistically significant. For Mexicans and IMG, the highest score was Internal Medicine, the lowest for Mexicans was Emergency Medicine and IMG Geriatrics. Table 2 depicts the means, SD, standard error of the mean between Mexicans and IMG for each clinical speciality; $p$-values were calculated with the independent t-test.

\section{Positive and Negative Trends in the Minimum and Maximum Scores vs Years (Mexicans and IMG) in each Clinical Speciality}

For the MinSco in Anesthesiology, only Mexicans showed a positive and significant correlation, $R=.849$, $\mathrm{p}=.008$; and for IMG $\mathrm{R}=-.511, \mathrm{p}=.196$. In Emergency medicine, both groups depicted a nonsignificant negative correlation, Mexicans $\mathrm{R}=$ $.446, p=.268$; IMG R $=-.298, p=.474$. For Geriatrics, both groups showed a positive non-signicant association; Mexicans $R=.333, p=.420$; IMG $R=$ $.059, \mathrm{p}=.941$. Internal medicine showed a similar behaviour than Geriatrics, Mexicans $R=.225, p=.591$; IMG $R=.095, p=.823$. In Medical Genetics Mexicans had a positive non-signicant correlation,

$\mathrm{R}=.612, \mathrm{p}=.107$; while in IMG the correlation was negative and nonsignificant, $R=-.102, p=.810$. Pediatrics presented a strong, positive significant correlation in Mexicans $\mathrm{R}=.743, \mathrm{p}=.035$; while IMG had a positive non-signicant one, $\mathrm{R}=.666, \mathrm{p}=.071$. Pneumology the corrrelation for this specialty was calculated only for Mexicans, $R=.480, p=.228$; the IMG group did not have enough test-takers in different years to calculate those values. Finally, in Psychiatry, both groups depicted a significant, positive correlation between the MinSco and the years of exam; Mexicans $\mathrm{R}=.820, \mathrm{p}=.013 ; \mathrm{IMG} \mathrm{R}=.866, \mathrm{p}=.012$.

For the Maximum score, in Anesthesiology, both groups had a non-significant correlation, negative in Mexicans $\mathrm{R}=-.187, \mathrm{p}=.657$; and positive in IMG $\mathrm{R}=$ $.271, p=.516$. Emergency medicine, showed a similar nonsignificant trend; negative in Mexicans $R=-.006, p$ 
Table 2: Comparison of Scores between Mexican and International Medical Graduates

\begin{tabular}{|c|c|c|c|c|c|c|c|}
\hline \multicolumn{8}{|c|}{ Minimum scores } \\
\hline \multirow[t]{2}{*}{ Specialities } & \multicolumn{3}{|c|}{ Mexican } & \multicolumn{3}{|c|}{ IMG } & \multirow[t]{2}{*}{ p-value } \\
\hline & Mean & Std. Deviation & Std. Error Mean & Mean & Std. Deviation & Std. Error Mean & \\
\hline Internal medicine & 71.806 & 1.293 & 0.457 & 72.028 & 1.292 & 0.457 & 0.736 \\
\hline Pneumology & 71.083 & 1.957 & 0.692 & 74.222 & - & - & 0.174 \\
\hline Geriatrics & 69.611 & 1,439 & 0.509 & 69.778 & 1.787 & 0.894 & 0.864 \\
\hline Psychiatry & 68.917 & 1.382 & 0.489 & 70.444 & 2.124 & 0.803 & 0.118 \\
\hline Pediatrics & 68.861 & 1.928 & 0.682 & 69.194 & 1.896 & 0.670 & 0.733 \\
\hline Medical Genetics & 68.778 & 0.742 & 0.262 & 69.916 & 1.585 & 0.560 & 0.096 \\
\hline Anesthesiology & 66.472 & 1.626 & 0.575 & 68.972 & 1.306 & 0.462 & $0.004^{*}$ \\
\hline Emergency medicine & 63.639 & 1.991 & 0.704 & 65.000 & 2.219 & 0.785 & 0.218 \\
\hline \multicolumn{8}{|c|}{ Máximum scores } \\
\hline \multirow[t]{2}{*}{ Specialities } & \multicolumn{3}{|c|}{ Mexican } & \multicolumn{3}{|c|}{ IMG } & \multirow[t]{2}{*}{ p-value } \\
\hline & Mean & Std. Deviation & Std. Error Mean & Mean & Std. Deviation & Std. Error Mean & \\
\hline Internal medicine & 86.944 & 1.561 & 0.552 & 80.917 & 2.045 & 0.723 & $<0.000^{*}$ \\
\hline Pediatrics & 85.222 & 2.047 & 0.724 & 76.861 & 2.045 & 0.723 & $<0.000^{*}$ \\
\hline Anesthesiology & 83.278 & 2.357 & 0.833 & 79.611 & 2.775 & 0.981 & $0.013^{*}$ \\
\hline Psychiatry & 82.222 & 1.926 & 0.681 & 73.365 & 2.516 & 0.951 & $<0.000^{*}$ \\
\hline Geriatrics & 81.556 & 1.671 & 0.591 & 69.778 & 1.787 & 0.894 & $<0.000^{*}$ \\
\hline Pneumology & 81.361 & 2.341 & 0.828 & 74.222 & - & - & $0.024^{*}$ \\
\hline Medical Genetics & 80.944 & 2.183 & 0.772 & 72.209 & 2.592 & 0.916 & $<0.000^{*}$ \\
\hline Emergency medicine & 80.000 & 2.181 & 0.771 & 72.195 & 3.496 & 1.236 & $<0.000^{*}$ \\
\hline
\end{tabular}

$=.989 ;$ and positive in IMG $\mathrm{R}=.317, \mathrm{p}=.444$. Geriatrics repeated the trend of the two previos specialties; Mexicans $\mathrm{R}=-.264, \mathrm{p}=.528$; IMG $\mathrm{R}=$ $.059, \mathrm{p}=.941$. Internal medicine showed a positive non-signicant correlation for both groups; Mexicans $\mathrm{R}=$ $.075, \mathrm{p}=.860 ;$ IMG $\mathrm{R}=.631, \mathrm{p}=.094$. Medical Genetics Mexicans had a negative, nonsignificant association, $\mathrm{R}=-.077, \mathrm{p}=.856$; while a positive, nonsignificant correlation in IMG, $R=.251, p=.548$. Pediatrics presented a strong, positive significant correlation in Mexicans $\mathrm{R}=.791, \mathrm{p}=.019$; while IMG had a weak, positive, non-signicant one, $R=.016, p=$ .970. Pneumology the corrrelation for this specialty was calculated only for Mexicans, $R=-.014, p=.974$; the IMG group did not have enough test-takers in different years to calculate those values. Finally, in Psychiatry, Mexicans had a positive nonsignificant correlation $\mathrm{R}=$ $.471, p=.239$; while it was negative, and nonsignificant for IMG $R=-.237, p=.609$. Table 3 shows a table of the correlations between the minimum and maximum scores vs years (up and down arrows) grouped by Mexican or IMG and their statistical significance.

\section{Modelling of Linear Trends}

All linear trend models were computed for the median Maximum or Minimum given years according to the formula:

Type of test-taker * (Year of years + Intercept)

Table 4 shows the R-Squared and p-values of the trend lines for the minimum and maximum scores grouped by the eight selected specialities. Figure 2 depicts the mathematical model for each trend lines grouped by medical speciality.

Figure 3 shows the graphical representation of the observed means and linear trends for both Min and Max scores.

\section{Comparison of 5-Year Forecasting Trends between the Minimum and Maximum Scores of Mexicans and IMG}

We identified convergent and divergent forecasting trends between each speciality's minimum and 
Table 3: Significant Trends in the Minimum and Maximum Scores between Mexican and International Medical Graduates

\begin{tabular}{|c|c|c|c|c|c|}
\hline \multirow[t]{2}{*}{ Score } & \multirow[t]{2}{*}{ Test-taker } & \multicolumn{4}{|c|}{ Medical specialty } \\
\hline & & Significant & Trend & Non-significant & Trend \\
\hline \multirow{8}{*}{ Minimum } & \multirow{3}{*}{ Mexican } & Anesthesiology & $\uparrow$ & Emergency medicine & $\downarrow$ \\
\hline & & Psychiatry & $\uparrow$ & Internal medicine & $\uparrow$ \\
\hline & & & & Medical Genetics & $\uparrow$ \\
\hline & \multirow{5}{*}{$\begin{array}{c}\text { International } \\
\text { Medical Graduates }\end{array}$} & & & Emergency medicine & $\downarrow$ \\
\hline & & & & Geriatrics & $\uparrow$ \\
\hline & & & & Internal medicine & $\uparrow$ \\
\hline & & & & Medical Genetics & $\downarrow$ \\
\hline & & & & Paediatrics & $\uparrow$ \\
\hline \multirow{10}{*}{ Maximum } & \multirow{4}{*}{ Mexican } & & & Internal medicine & $\uparrow$ \\
\hline & & & & Medical Genetics & $\downarrow$ \\
\hline & & & & Pneumology & $\downarrow$ \\
\hline & & & & Psychiatry & $\uparrow$ \\
\hline & \multirow{6}{*}{$\begin{array}{c}\text { International } \\
\text { Medical Graduates }\end{array}$} & & & Anesthesiology & $\uparrow$ \\
\hline & & & & Emergency medicine & $\uparrow$ \\
\hline & & & & Geriatrics & $\uparrow$ \\
\hline & & & & Internal medicine & $\uparrow$ \\
\hline & & & & Medical Genetics & $\uparrow$ \\
\hline & & & & Paediatrics & $\uparrow$ \\
\hline
\end{tabular}

$\uparrow$ Positive growing trend; $\downarrow$ negative growing trend; * insufficient test-takers in different years to calculate the correlation.

Table 4: R-Squared and $p$-Values of the Trend Lines for the Minimum and Maximum Scores Grouped by the Eight Selected Specialities

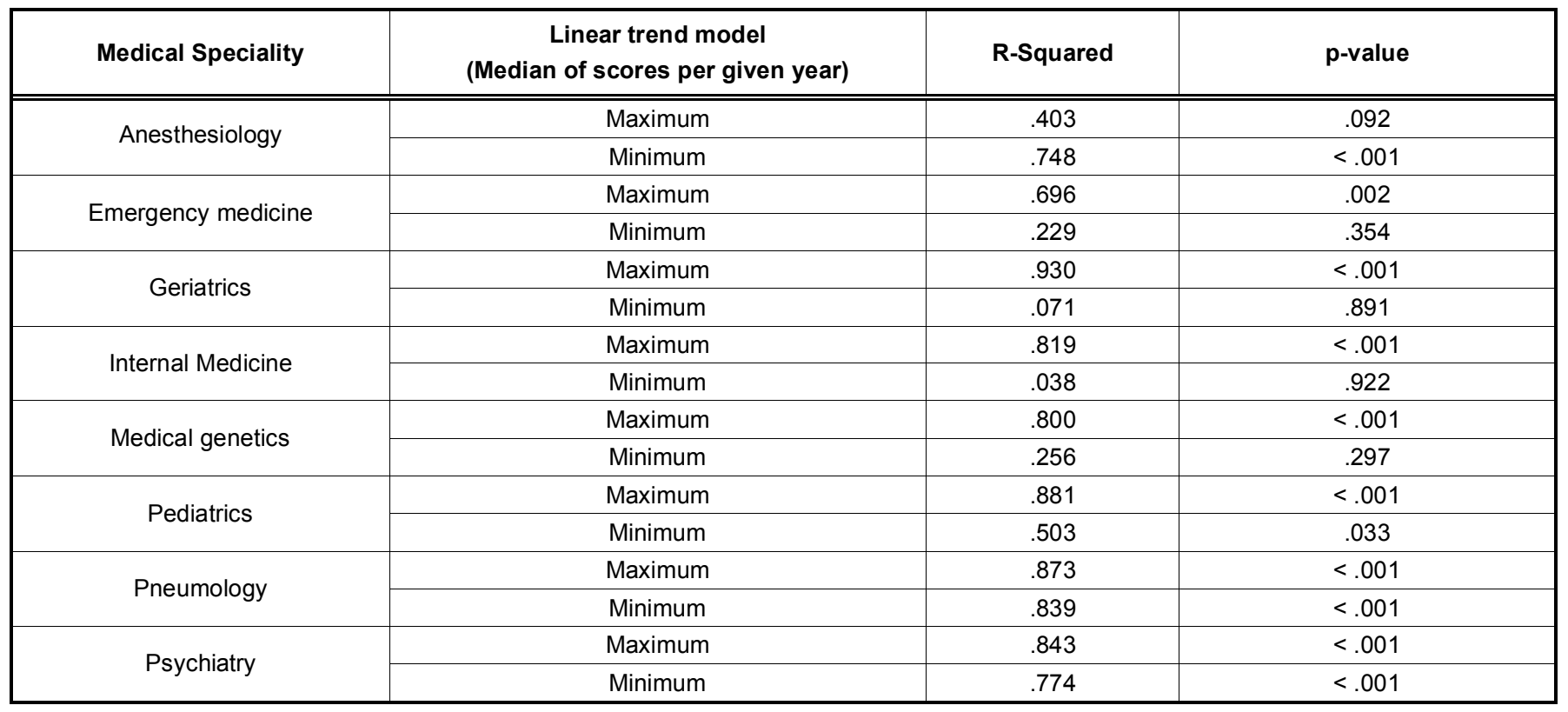




\begin{tabular}{|c|c|c|c|c|c|c|c|c|c|}
\hline \multirow{9}{*}{ Anesthesiology } & \multirow{3}{*}{$\begin{array}{l}\text { Panes } \\
\text { Row } \\
\text { Median Maximum }\end{array}$} & \multirow{3}{*}{$\frac{\text { Column }}{\mathrm{IMG}}$} & Line & DF & \multicolumn{5}{|c|}{ Coefficients } \\
\hline & & & 0.516546 & 6 & Year of Years 0 & 0.0008399 & 0.00121890 & 0.689036 & 0.516546 \\
\hline & & & & & intercept $\quad 4$ & 44.1793 & $51.4328 \quad 0$ & 0.858972 & 0.42334 \\
\hline & Median Maximum & Mexican & 0.657594 & 6 & Year of Years & -0.0004925 & $0.0010566-$ & $\begin{array}{ll}-0.466087 & 0\end{array}$ & 0.657594 \\
\hline & & & & & intercept $\quad 1$ & 104.053 & $44.583 \quad 2$ & $2.33393 \quad 0$ & 0.0583265 \\
\hline & Median Minimum & IMG & 0.195733 & 6 & Year of Years & -0.0007457 & $0.0005123-1$ & -1.45566 & 0.195733 \\
\hline & & & & & intercept 1 & 100.4332 & $21.6172 \quad 4$ & 4.64599 & 0.0035184 \\
\hline & Median Minimum & Mexican & 0.007687 & 6 & Year of Years 0 & 0.0015426 & 0.00039223 & $3.9329 \quad 0$ & 0.007687 \\
\hline & & & & & intercept $\quad 1$ & 1.39315 & $16.5506 \quad 0$ & 0.08417520 & 0.935655 \\
\hline & $\begin{array}{l}\text { Panes } \\
\text { Row }\end{array}$ & Column & $\begin{array}{l}\text { Line } \\
\text { p-value }\end{array}$ & DF & $\begin{array}{l}\text { Coefficients } \\
\text { Term }\end{array}$ & Value & StdErr $t$ & t-value & p-value \\
\hline & $\overline{\text { Minimum }}$ & $\overline{\mathrm{IMG}}$ & 0.473805 & $\overline{6} \bar{Y}$ & Year of Years & -0.0007386 & 0.0009667 & -0.764046 & 0.473805 \\
\hline Emergency & & & & & intercept $\quad 9$ & 96.1591 & $40.7899 \quad 2$ & 2.35742 & 0.0564825 \\
\hline Medicine & Minimum & Mexican & 0.268257 & 6 & Year of Years - & -0.000992 & 0.0008132 & -1.21995 & 0.268257 \\
\hline & & & & & intercept $\quad 1$ & 105.49 & $34.3123 \quad 3$ & 3.0744 & 0.0218188 \\
\hline & Maximum & IMG & 0.444152 & 6 & Year of Years 0 & 0.001239 & 0.001513 & 0.818887 & 0.444152 \\
\hline & & & & & intercept $\quad 1$ & 19.9239 & 63.844 & 0.312072 & 0.765547 \\
\hline & Maximum & Mexican & 0.98945 & 6 & Year of Years & $-1.371 \mathrm{e}-05$ & 0.000995 & -0.0137834 & 0.98945 \\
\hline & & & & & intercept 8 & 80.5784 & 41.9843 & 1.91925 & 0.103373 \\
\hline & Panes & & Line & & Coefficients & & & & \\
\hline & Row & Column & p-value & $\underline{\text { DF }}$ & Term & Value & StdErr & t-value & p-value \\
\hline & Maximum & IMG & 0.940742 & 2 & Year of Years & $8.256 \mathrm{e}-05$ & 0.0009834 & 40.083951 & 0.940742 \\
\hline Geriatrics & Maximum & & & & intercept & 66.2952 & 41.5008 & 1.59744 & 0.251257 \\
\hline & & Mexican & 0.528611 & 6 & $\begin{array}{l}\text { Year of Years } \\
\text { intercept }\end{array}$ & $\begin{array}{l}-0.0004919 \\
102.309\end{array}$ & $\begin{array}{l}0.0007357 \\
31.0451\end{array}$ & $\begin{array}{l}-0.668615 \\
3.29549\end{array}$ & $\begin{array}{l}5.528611 \\
0.0165005\end{array}$ \\
\hline & Minimum & IMG & 0.940742 & 2 & Year of Years & $8.256 \mathrm{e}-05$ & 0.0009834 & 40.083951 & 0.940742 \\
\hline & & & & & intercept & 66.2952 & 41.5008 & 1.59744 & 0.251257 \\
\hline & Minimum & Mexican & 0.419588 & 36 & Year of Years & 0.0005362 & 0.000619 & 0.866351 & 0.419588 \\
\hline & & & & & intercept & 46.9886 & 26.1174 & 1.79913 & 0.122099 \\
\hline & Panes & & Line & & Coefficients & & & & \\
\hline & Row & Column & p-value & $\underline{\text { DF }}$ & F Term & Value & StdErr & t-value & p-value \\
\hline & Maximum & IMG & 0.0937266 & 66 & Year of Years & s 0.0014413 & 0.0007243 & 31.98992 & 0.0937266 \\
\hline Internal & & & & & intercept & 20.1108 & 30.5631 & 0.658008 & 0.534949 \\
\hline Medicine & Maximum & Mexican & 0.860043 & 6 & Year of Years & s 0.0001307 & 0.0007103 & 30.184042 & 0.860043 \\
\hline iviedicine & & IMG & & & intercept & 81.429 & 29.9738 & 2.71667 & 0.0347962 \\
\hline & Minimum & & 0.822643 & 6 & Year of Years & s 0.0001375 & 50.000587 & 0.234164 & 0.822643 \\
\hline & Minimum & Mexican & 0.591173 & & $\begin{array}{l}\text { Intercept } \\
\text { Year of Years }\end{array}$ & $\begin{array}{l}66.2285 \\
0.0003259\end{array}$ & 0.0005746 & $\begin{array}{l}6.07309 \\
0.567166\end{array}$ & 0.591173 \\
\hline & & & & . & intercept & 58.0573 & 24.2449 & 2.39462 & 0.0536874 \\
\hline & Panes & & Line & & Coefficients & & & & \\
\hline & Row & Column & p-value & $\underline{\mathrm{DF}}$ & Term & Value & StdErr & t-value & p-value \\
\hline & Minimum & IMG & 0.81012 & 6 & Year of Years - & -0.0001806 & 0.0007193 & -0.251094 & 0.81012 \\
\hline Medical & Minimum & Mexican & 0.107086 & 6 & $\begin{array}{l}\text { intercept } \\
\text { Year of Years }\end{array}$ & 77.5357 & 30.3505 & 2.55468 & 0.0432173 \\
\hline & & & & & $\begin{array}{l}\text { Year of Years } \\
\text { intercept }\end{array}$ & $\begin{array}{l}0.000507 \\
47.3884\end{array}$ & $\begin{array}{l}0.0002677 \\
11.2967\end{array}$ & $\begin{array}{l}1.8938 \\
4.19488\end{array}$ & $\begin{array}{l}0.107086 \\
0.0057182\end{array}$ \\
\hline & Maximum & IMG & 0.548233 & 6 & Year of Years & 0.000728 & 0.0011446 & 0.636033 & 0.548233 \\
\hline & & & & & intercept & 41.4945 & 48.2994 & 0.859111 & 0.423269 \\
\hline & Maximum & Mexican & 0.856099 & 6 & Year of Years - & -0.000188 & 0.0009931 & -0.189299 & 0.856099 \\
\hline & & & & & intercept & 88.8749 & 41.9035 & 2.12094 & 0.0781815 \\
\hline & Panes & & Line & & Coefficients & & & & \\
\hline & Row & Column & p-value & $\underline{\text { DF }}$ & Term & Value & StdErr & t-value & p-value \\
\hline & Maximum & IMG & 0.970326 & 6 & Year of Years & s $3.618 \mathrm{e}-05$ & 0.0009329 & 0.0387779 & 90.970326 \\
\hline & & & & & intercept & 75.3351 & 39.3644 & 1.91379 & 0.104159 \\
\hline Pediatrics & Maximum & Mexican & 0.0192771 & 16 & Year of Years & s 0.0018107 & 0.0005709 & 3.17171 & 0.0192771 \\
\hline & & & & & intercept & 8.831 & 24.0899 & 0.366585 & 0.726509 \\
\hline & Minimum & IMG & 0.0711102 & 26 & Year of Years & s 0.0014126 & 0.0006451 & 2.18964 & 0.0711102 \\
\hline & & & & & intercept & 9.60087 & 27.2215 & 0.352695 & 0.736377 \\
\hline & Minimum & Mexican & 0.034747 & 6 & Year of Years & 50.0016006 & 0.000589 & 2.71774 & 0.034747 \\
\hline & & & & & intercept & 1.33455 & 24.8515 & 0.053701 & 0.958917 \\
\hline & Panes & & Line & & Coefficients & & & & \\
\hline & Row & Column & p-value & $\underline{\text { DF }}$ & Term & Value & $\underline{\text { StdErr }}$ & t-value & p-value \\
\hline & Minimum & IMG & 0.134037 & 6 & Year of Years & 0.0169313 & 0.0097772 & 1.73171 & 0.134037 \\
\hline & & & & & intercept & -705.016 & 412.559 & -1.70888 & 0.138332 \\
\hline Pneumology & Minimum & Mexican & 0.228283 & 6 & Year of Years & 0.0010508 & 0.0007832 & 1.34156 & 0.228283 \\
\hline & & & & & intercept & 26.7541 & 33.0496 & 0.809514 & 0.449123 \\
\hline & Maximum & IMG & 0.134037 & 6 & Year of Years & 0.0169313 & 0.0097772 & 1.73171 & 0.134037 \\
\hline & & & & & intercept & -705.016 & 412.559 & -1.70888 & 0.138332 \\
\hline & Maximum & Mexican & 0.974085 & 6 & Year of Years & $-3.617 e-05$ & 0.0010681 & -0.0338634 & $\begin{array}{ll}44 & 0.974085\end{array}$ \\
\hline & & & & & intercept $\quad \varepsilon$ & 82.8872 & 45.0703 & 1.83906 & 0.115528 \\
\hline & $\begin{array}{l}\text { Panes } \\
\text { Row }\end{array}$ & Column & $\begin{array}{l}\text { Line } \\
\text { p-value }\end{array}$ & DF & $\begin{array}{l}\text { Coefficients } \\
\text { Term }\end{array}$ & Value & StdErr & t-value & p-value \\
\hline & Maximum & IMG & 0.608887 & 5 & Year of Years & -0.000619 & 0.0011349 & -0.545446 & 60.608887 \\
\hline & & & & & intercept & 99.4631 & 47.858 & 2.0783 & 0.0922612 \\
\hline & Maximum & Mexican & 0.238782 & 6 & Year of Years & 50.0010142 & 0.0007754 & 1.30789 & 0.238782 \\
\hline sychiatry & & & & & intercept & 39.436 & 32.7203 & 1.20525 & 0.273481 \\
\hline & Minimum & IMG & 0.0116332 & 5 & Year of Years & 0.0019107 & 0.0004923 & 3.88074 & 0.0116332 \\
\hline & & & & & intercept & -10.113 & 20.7629 & -0.48707 & 0.64681 \\
\hline & Minimum & Mexican & 0.0126063 & 6 & Year of Years & 50.0012673 & 0.0003606 & 3.51424 & 0.0126063 \\
\hline & & & & & intercept & 15.4505 & 15.2171 & 1.01534 & 0.349125 \\
\hline
\end{tabular}

Figure 2: Mathematical model of individual trend lines for each medical speciality. 


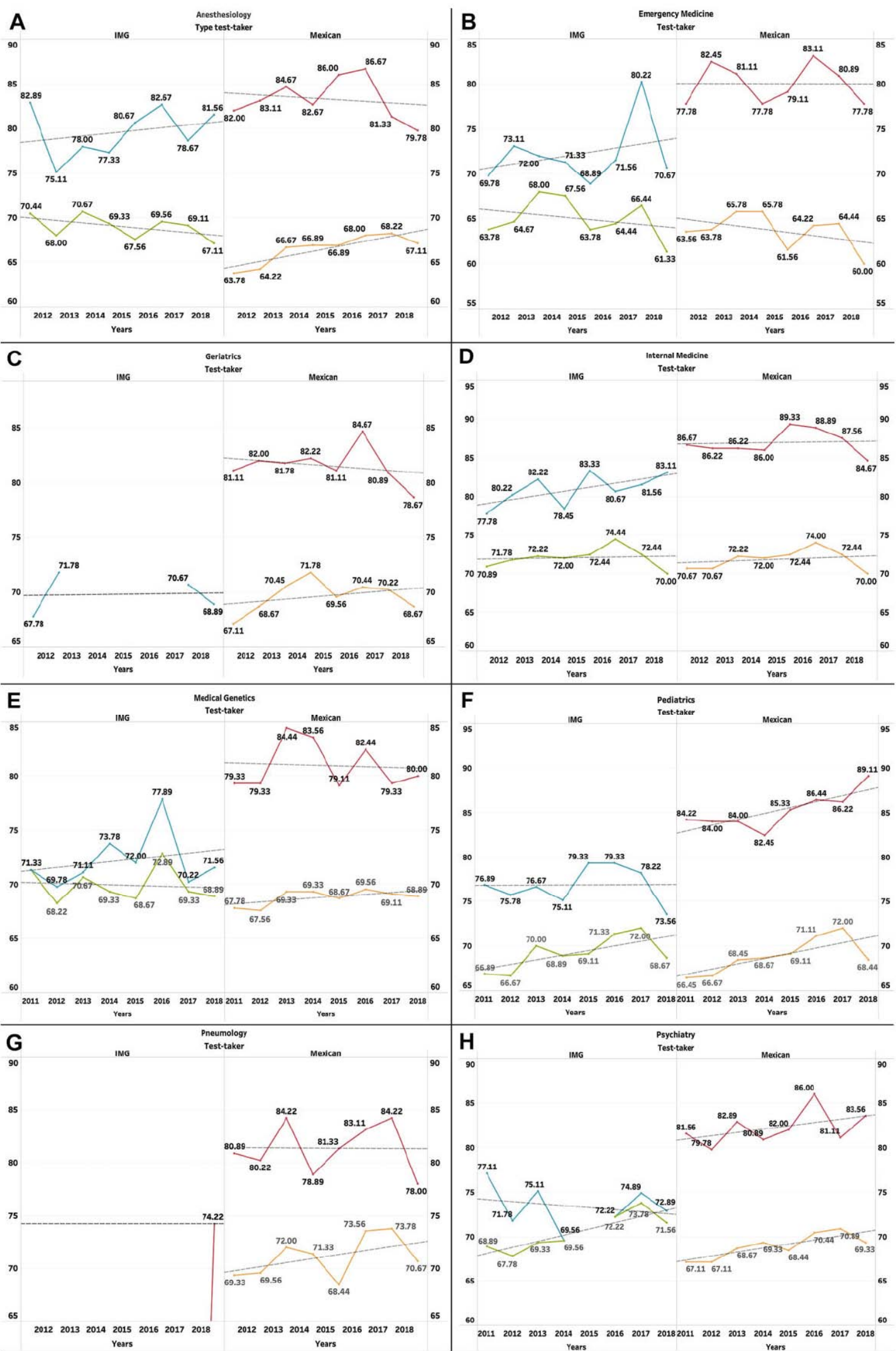

Mexican, Median Maximum

Figure 3: Selected specialities are showing increasing and decreasing trends in the SMinS and SMaxS. 


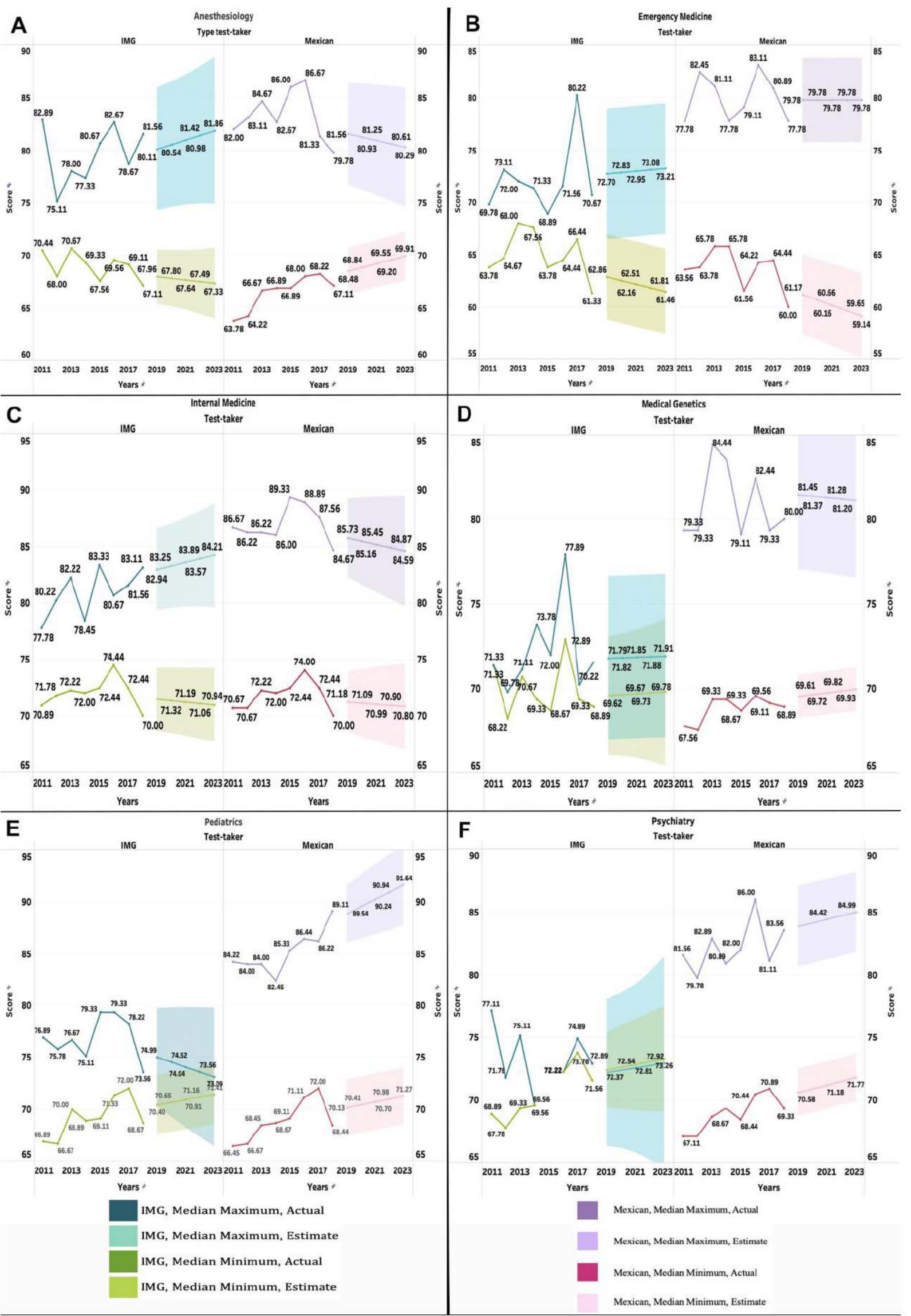

Figure 4: Forecasted trends between the minimum and maximum scores of Mexicans and IMG. 
Median Maximum

\begin{tabular}{|c|c|c|c|c|c|c|c|c|c|c|}
\hline Column & Color & & Model & & & Quality Met & trics & Smooth & hing $\mathrm{C}$ & efficients \\
\hline ype test-taker & Type test-taker & Level & Trend & Season & RMSE & MAE MASE & MAPE AIC & Alpha & Beta & Gamma \\
\hline MG & IMG & Additive & Additive & None & 3 & 20.73 & $3.1 \% \quad 27$ & 0.141 & 0.500 & 0.000 \\
\hline Mexican & Mexican & Additive & Additive & None & 2 & 0.96 & $2.5 \%$ & 0.298 & 0.00 & 0.000 \\
\hline
\end{tabular}

Anesthesiology

Median Minimum

Column Color Model Quality Metrics Smoothing Coefficients

Type test-taker Type test-taker Level Trend Season RMSE MAE MASE MAPE AIC Alpha Beta Gamma

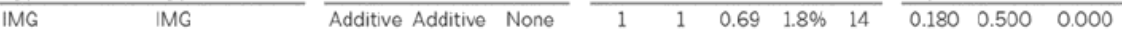

$\begin{array}{llllllllllll}\text { Mexican } & \text { Mexican } & \text { Additive Additive None } & 1 & 1 & 1.10 & 1.3 \% & 12 & 0.100 & 0.354 & 0.000\end{array}$

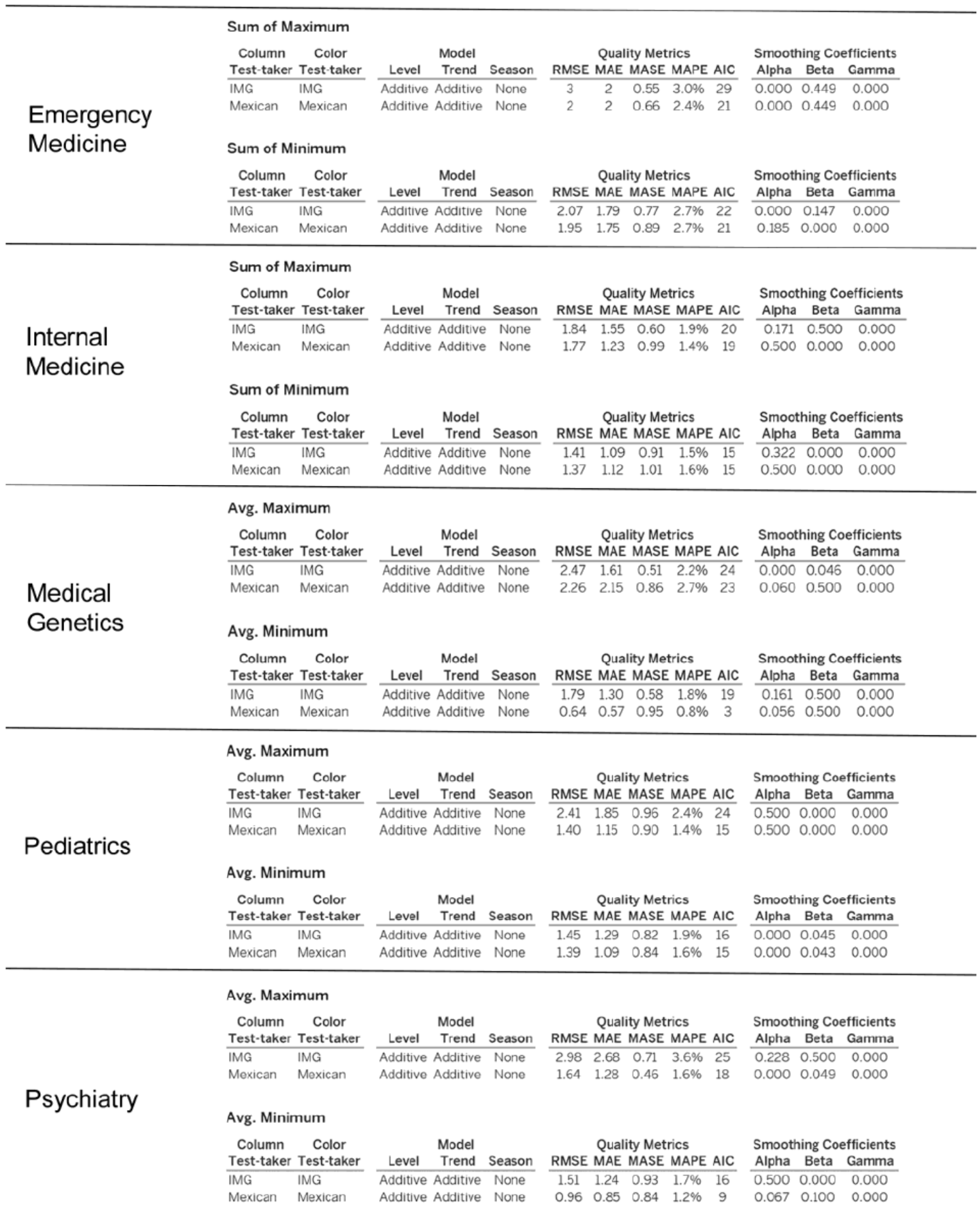

Figure 5: Description of the forecasting models grouped by speciality. Geriatrics and Pneumology were not included due to fewer years that did not allow for calculated reliable models. 
maximum scores, depending on if the lines will or will not eventually touch each other during or after a 5-year forecasted period (2020-2024 years).

Five specialities showed a convergent pattern for Mexicans between the MinSco and MaxSco: Anesthesiology, Internal medicine, Medical Genetics, Geriatrics, and Pneumology, and three a divergent pattern: Emergency medicine, Pediatrics, Psychiatry.

In IMG, one speciality depicted a convergent trend: Pediatrics; five specialities had a divergent tendency: Anesthesiology, Internal medicine, Medical Genetics, Emergency medicine, Pediatrics, Psychiatry. For Geriatrics and Pneumology, because there were not test-takers in all the evaluated years, for that reason, the software could not calculate forecasting graphs. Figure 4 shows the forecasted trends between MinSco and MaxSco for Mexicans and IMG.

Figure 5 presents the description of the forecasted models grouped by speciality (definitions for the different components were described in the methods sections).

\section{Ranking of Specialities between Mexicans and IMG}

Additionally, we ranked the specialities based on the MinSco between Mexicans and IMG for each speciality. Adjacent rows with connecting arrows show the displacement in the ranking from the initial rank each speciality reached for Mexicans compared with their position for IMG.
For the MinSco, it was evident that the ranking of medical specialities was different between both groups: three specialities in the Mexican ranking (Pneumology, psychiatry, and Medical genetics) went up when compared them with the IMG; three moves down (Internal medicine, Geriatrics, and Pediatrics), and only two (Anesthesiology and Emergency medicine) depicted the same raking for Mexicans and IMG.

For the MaxSco, the ranking of medical specialities was different in almost all the specialities between both groups: four specialities went up in the Mexican ranking (Anesthesiology, Pneumology, Emergency medicine, and Medical genetics) after compared them with the IMG; three moves down (Psychiatry, Geriatrics, and Pediatrics), and only Internal medicine depicted the same raking for Mexicans and IMG. Figure 6 showed the ranking displacement in Mexican specialities (MinSco and MaxSco) when we compared them with the scores of IMG.

\section{DISCUSSION}

Residency is a critical step in a physician's education; the matching into a residency program is a competitive process of selection by both applicants and program directors [23]. Residency program directors usually do not make a decision based only on the test scores of the applicants. They must have a more comprehensive evaluation and therefore receive large amounts of information about applicants, including academic transcripts, the medical student performance assessment, letters of recommendation and others

\begin{tabular}{|c|c|c|c|c|c|c|}
\hline \multicolumn{2}{|r|}{ Mexican } & \multirow{2}{*}{\multicolumn{3}{|c|}{ Minimum score }} & \multicolumn{2}{|l|}{ IMG } \\
\hline \multirow{2}{*}{$\frac{\text { Ranking }}{1}$} & \multirow{2}{*}{$\begin{array}{c}\text { Specialty } \\
\text { Internal medicine } \\
\end{array}$} & & & & \multirow{2}{*}{$\begin{array}{c}\text { Specialty } \\
\text { Pneumology }\end{array}$} & \multirow{2}{*}{$\begin{array}{c}\text { Ranking } \\
2\end{array}$} \\
\hline & & 71.806 & & 74.222 & & \\
\hline 2 & Pneumology & 71.083 & & 72.028 & Internal medicine & 1 \\
\hline 3 & Geriatrics & 69.611 & & 70.444 & Psychiatry & 4 \\
\hline 4 & Psychiatry & 68.917 & & 69.916 & Medical Genetics & 6 \\
\hline 5 & Pediatrics & 68.861 & & 69.778 & Geriatrics & 3 \\
\hline 6 & Medical Genetics & 68.778 & & 69.194 & Pediatrics & 5 \\
\hline 7 & Anesthesiology & 66.472 & & 68.972 & Anesthesiology & 7 \\
\hline 8 & Emergency medicine & 63.639 & & 65.000 & Emergency medicine & 8 \\
\hline \multicolumn{2}{|r|}{ Mexican } & \multirow{2}{*}{\multicolumn{3}{|c|}{ Maximum score }} & \multicolumn{2}{|l|}{ IMG } \\
\hline Ranking & Specialty & & & & Specialty & Ranking \\
\hline 1 & Internal medicine & 86.944 & & 80.917 & Internal medicine & 1 \\
\hline 2 & Pediatrics & 85.222 & & 79.611 & Anesthesiology & 3 \\
\hline 3 & Anesthesiology & 83.278 & & 76.861 & Pediatrics & 2 \\
\hline 4 & Psychiatry & 82.222 & & 74.222 & Pneumology & 6 \\
\hline 5 & Geriatrics & 81.556 & & 73.365 & Psychiatry & 4 \\
\hline 6 & Pneumology & 81.361 & & 72.209 & Medical Genetics & 7 \\
\hline 7 & Medical Genetics & 80.944 & & 72.195 & Emergency medicine & 8 \\
\hline 8 & Emergency medicine & 80.000 & & 69.778 & Geriatrics & 5 \\
\hline
\end{tabular}

Figure 6: Ranking displacement in Mexican specialities when compared with the scores of IMG. 
[24]; a 2006 survey evinced that 2,528 program directors chose top academic selection criteria based on clinical performance [25].

Thus, the results will benefit four groups of actors interested in the processes of a successful match: ENARM applicants, education department directors, medical school advisors, and medical students who are planning to enter a residency program. The strengths of our study lie in different approaches to analyze the information. We compared the means in eight clinical specialities, the differences between Mexicans and IMG scores, calculated correlations and linear trends, 5-years forecasting, and ranking displacement for Mexicans and IMG in each speciality. Reporting information about a pattern in the assessments across specialities has been considered valuable to residents and program directors [26].

\section{Educational Framework}

The preparation for the exam should: motivate the learner through improvement in real-life, final performance; take into account the learner's preexisting knowledge (learning curve); allow repetition of the skills multiple times; be accompanied by immediate feedback, and be varied (mixed) across content areas. We think the significantly different scores between Mexicans and IMG might primarily represent a lack of practice and direct supervision of skills acquisition (answering previous exam models). Knowing in advance, the clinical field scores are relevant to predicting the performance during the residence. As it was evinced in a recent article of 2019, the performance of USMLE Step 2 CK correlated with higher scores during residence tests with better clinical performance [24].

Publications about the Mexican ENARM have triggered a great interest in the medical community in the last years; some authors have published descriptive reports about the scores of schools and faculties of medicine [3]; other authors have revealed flaws in the design of the ENARM that produce inequity, $[6,27]$; a recent study was published about the performance of IMG in the ENARM but without a comparison with Mexicans [8]. To the best of our knowledge, there are no publications about the ENARM that had presented a comparison of scores in clinical specialities between Mexicans and IMG; that situation did not allow us to compare most of our results with others literature.

\section{Grouping of Specialities above or below a Global Mean}

The use of an overall mean to compare above or below this mark is helpful to reflect the performance of eight different groups of test-takers that revealed to us which specialities had the students with the best scores. The ENARM global mean for the minimum score (from 2012 to 2019) was 69.133, a score above the previous observation made in a study by de la Garza-Aguilar [4]; this number is also above the mean for the last seven years for the test known as MIR (Medical Intern Resident) in Spain with 57.29 reported by the Ministry of Health [28, 29]. Our findings showed that the clinical specialities whose applicants achieved scores above this mean were Internal medicine, Anesthesiology, Pediatrics, and Pneumology. This observation of high scores at the ENARM contrasts with the matching program results in the USA [30, 31]. The specialities below the mean corresponded to Emergency Medicine and Anesthesiology.

\section{Comparison of Minimum and Maximum Scores Achieved by Clinical Specialities}

During the eight years assessed, it was evident that the eight clinical specialities' ranking was preserved for the MinSco (Figure 1D), specialities in the upper values were internal medicine and Pneumology, and in the lower values emergency medicine and anesthesiology. On the contrary, for the MaxSco, although there is an entanglement of scores was evident along the eight years, representing the change of ranking for the clinical specialities at different years, internal medicine and emergency medicine are dominant with the upper and lower scores (Figure 1C).

\section{Comparison of Minimum and Maximum Scores between Mexicans and IMG in each Clinical Speciality}

Our findings revealed that Mexicans and IMG got mostly similar passing grades, which might indicate an equivalent level of education in their medical schools; however, for Pneumology, anesthesiology, and emergency medicine, the IMG got up to $2 \%$ points in higher scores (Table 2). This finding differs from a previous report from the USA observed in 8 years for the orthopaedic surgery residency applicants that national got better scores than IMG [32]. The absence of significant differences in the minimum scores in most specialities comparing Mexican and IMG can also be interpreted as high competitiveness across all specialities (Table 2). However, MaxSco revealed the 
superiority of Mexicans above IMG for all specialities, and all specialities showed a significant difference (Table 2), which reflected a better level of preparation for this exam. This score revealed a significant gap in knowledge between Mexicans and IMG test-takers [33].

Positive and Negative Trends in the Minimum and Maximum Scores between Mexicans and IMG in each Surgical Specialities

The limited information about trends for applicants matching into USA specialities has been previously addressed. Most foreign articles describe specific specialities' performance without comparing their nationals and IMG [34]. We learned from our findings that there is still missing information, and we do not know which scores at specialities are ruled by the applicants every year and which others by the level of difficulty of the exam; an additional analysis will be necessary to understand how the number of residency positions influences the scores at each medical speciality.

\section{Comparison of 5-Year Forecasting Trends between the Minimum and Maximum Scores of Mexicans and IMG}

The predictive graphs help us understand that for Mexicans, the gap between MinSco and MaxSco will decrease for Anesthesiology, Internal medicine, and Medical genetics. However, for IMG Pediatrics and medical genetics. It means there are only 3 out of 8 surgical specialities (Emergency medicine, medical genetics, and Psychiatry) between Mexicans and IMG that share the same learning trend.

\section{Ranking of Specialities between Mexicans and IMG}

From this analysis, we learned that Mexicans achieved higher scores for MaxSco in the eight clinical specialities; on the contrary, IMG got higher values for their MinSco (Figure 4). For the MaxSco, the $1^{\text {st }}$ speciality with the highest scores is Internal medicine. This fact represents a challenge for future applicants, as they would have to get the best scores to be selected for a residency position. (Figure 4).

\section{Limitations of the Study}

Several limitations need to be acknowledged for this study. With the ENARM, the Mexican Secretariat of Health selects the best candidates each year with reasonable confidence, but a number much higher than the accepted is left without entering a medical speciality; we did not analyze those numbers as this topic was out of the scope of this study. Also, we did not comment on the context regarding the offer and demand of Mexican physicians per number of inhabitants; in 2015, Mexico had 2.2 physicians per 1,000 population, including professionals in the private sector, these numbers represent a significant disparity in the distribution of human health resources in the country. We did not understand which medical schools corresponded the test-takers with the highest scores, as this information was not available in the annual CIFRHS reports. Our assessment did not perform subgroup performance differences considering age, gender, test-takers race, and English as a second language because all these items were not publicly available. The same limitations had been addressed in previous reports for USMLE; residency program directors look in the ENARM results for the best candidates for their programs, considering all aspects of a student's application and an interview; however, we did not take into account intangible factors such as away rotations, personal interactions, membership, and research experience, although all of them might influence the chance of matching [23], these variables were not assessed in the context of this paper. Other topics no included in this study were the need to examine whether there is an ideal applicant-to-position ratio that would allow clinical residency coordinators to remain selective in their choices or whether increasing the number of clinical residency positions would dilute the quality of successful candidates.

In conclusion, our study provides objective and valuable information for residency program directors looking for the best candidates for their programs and also to applicants, revealing that ENARM represents a market of high-performance test-takers across the clinical specialities. Mexicans and IMG achieved similar entrance scores, but Mexicans showed a higher MaxSco than IMG in all clinical specialities. The comparisons using scores will allow program directors to compare academic performance across specialities and understand their competitiveness and evolution in recent years. Future studies are needed to explore if ENARM scores can predict performance on subsequent speciality assessments in training and certification examinations.

\section{REFERENCES}

[1] Akaki Blancas JL, López Bárcena J. Formación de médicos especialistas en México. Educación Médica 2018; 19: 36-42. https://doi.org/10.1016/j.edumed.2018.03.007 
[2] OCDE. Health at a Glance 2015 OECD INDICATORS 2015. $220 \mathrm{p}$.

[3] Ramiro HM, Cruz AJ, Zeron-Gutierrez L, Arevalo-Vargas A. [The ENARM and the schools and faculties of medicine. An analysis that nobody will like]. Rev Med Inst Mex Seguro Soc 2017; 55(4): 498-511.

[4] de la Garza-Aguilar J. [Reflections on the quality of medical school curricula in Mexico]. Gac Med Mex 2005; 141(2): 12941.

[5] Barajas-Ochoa A, Ramos-Remus C. [Equity, validity and reliability of the National Examination for Candidates to Medical Residences (ENARM): opportunities for improvement]. Salud Publica Mex 2017; 59(5): 501-2. https://doi.org/10.21149/8769

[6] Barajas-Ochoa A, Ramos-Remus C, Castillo-Ortiz JD, Yanez J, Barajas-Ochoa Z, Sanchez-Gonzalez JM, et al. Flaws in the design of the Examen Nacional para Aspirantes a Residencias Medicas produce inequity. Salud Publica Mex 2019; 61(2): 125-35.

https://doi.org/10.21149/9790

[7] Secretaria_de_Salud_Comisión_Interinstitucional_para_la_F ormación_de_Recursos_Humanos_para_la_Salud. Reportes academicos. Informacion por año. Mexico City 2018 [Access date: May 16, 2019].

[8] Mendoza-Aguilar AN, Salazar-Ruiz SY, Cardiel-Marmolejo LE, Roldan-Valadez E. Comparison of scores achieved by foreign medical graduates in the National Evaluation for Medical Residency (ENARM) in Mexico. Postgrad Med J 2019. https://doi.org/10.1136/postgradmedj-2019-136893

[9] Blog_ENARM_by_Foro_ENARM.org. Mejores Escuelas y Facultades de Medicina - Ranking 2018 Mexico City: Foro_ENARM.org; 2018 [Date cited: Oct 02, 2019]. Available from: https://comunidadenarm.blogspot.com].

[10] Bordage G. Conceptual frameworks to illuminate and magnify. Med Educ 2009; 43(4): 312-9.

https://doi.org/10.1111/j.1365-2923.2009.03295.x

[11] CIFRHS. Examen Nacional para Aspirantes a Residencias Médicas: INFORMACIÓN POR AÑO 2019 [Access: March 05th, 2020]. Available from: http://www.cifrhs.salud.gob.mx/site1/enarm/enarm_ia.html.

[12] Hernandez-Galvez DC, Roldan-Valadez E. Mexican ENARM: performance comparison of public vs. private medical schools, geographic and socioeconomic regions. Salud publica de Mexico 2019; 61. https://doi.org/10.21149/10078

[13] CIFRHS. Examen Nacional para Aspirantes a Residencias Médicas: Puntajes máximos y mínimos por especialidad de médicos mexicanos civiles y lugares de médicos extranjeros seleccionados 2019 [Access: March 05th, 2020]. Available from: http://www.cifrhs.salud.gob.mx/site1/enarm/ docs/2019/E43_puntajes_max_min_2019.pdf.

[14] CIFRHS. The Interinstitutional Commission for Human Resources Training for Health. Mexican Ministry of Health. XXXIX Examen Nacional para Aspirantes a Residencias Médicas. Convocatoria 2015. Mexico City: Mexican government; 2015 [Access date October 04 th, 2019]. Available from: http://www.cifrhs.salud.gob.mx/site1/enarm/ docs/2015/E39_convo_2015.pdf.

[15] Roldan-Valadez E, Rios-Piedra E, Favila R, Alcauter S, Rios C. Diffusion tensor imaging-derived measures of fractional anisotropy across the pyramidal tract are influenced by the cerebral hemisphere but not by gender in young healthy volunteers: a split-plot factorial analysis of variance. Chin Med J (Engl) 2012; 125(12): 2180-7.

[16] Lopez-Mejia M, Roldan-Valadez E. Comparisons of Apparent Diffusion Coefficient Values in Penumbra, Infarct, and Normal Brain Regions in Acute Ischemic Stroke: Confirmatory Data Using Bootstrap Confidence Intervals,
Analysis of Variance, and Analysis of Means. J Stroke Cerebrovasc Dis 2016; 25(3): 515-22.

https://doi.org/10.1016/j.jstrokecerebrovasdis.2015.10.033

[17] Pfister R, Janczyk M. Confidence intervals for two sample means: Calculation, interpretation, and a few simple rules. Advances in cognitive psychology / University of Finance and Management in Warsaw 2013; 9(2): 74-80.

https://doi.org/10.5709/acp-0133-x

[18] Cohen JW. Statistical power analysis for the behavioral sciences. 2nd ed. Hillsdale, NJ: Lawrence Erlbaum Associates; 1988.

[19] Chatfield C. he Holt-Winters Forecasting Procedure. Applied Statistics 1978; 27(3): 264-79. https://doi.org/10.2307/2347162

[20] Adeyinka DA, Muhajarine N. Time series prediction of underfive mortality rates for Nigeria: comparative analysis of artificial neural networks, Holt-Winters exponential smoothing and autoregressive integrated moving average models. BMC Med Res Methodol 2020; 20(1): 292.

https://doi.org/10.1186/s12874-020-01159-9

[21] Talkhi N, Akhavan Fatemi N, Ataei Z, Jabbari Nooghabi M. Modeling and forecasting number of confirmed and death caused COVID-19 in IRAN: A comparison of time series forecasting methods. Biomed Signal Process Control 2021; 66: 102494. https://doi.org/10.1016/j.bspc.2021.102494

[22] TABLEAU_SOFTWARE_LLC. Forecast Descriptions. Seattle, Washington. [cited May 12, 2021]. Available from: https://help.tableau.com/current/pro/desktop/enus/forecast_describe.htm.

[23] Rinard JR, Mahabir RC. Successfully matching into surgical specialties: an analysis of national resident matching program data. Journal of graduate medical education 2010; 2(3): 316-21. https://doi.org/10.4300/JGME-D-09-00020.1

[24] Sharma A, Schauer DP, Kelleher M, Kinnear B, Sall D, Warm E. USMLE Step 2 CK: Best Predictor of Multimodal Performance in an Internal Medicine Residency. Journal of graduate medical education 2019; 11(4): 412-9. https://doi.org/10.4300/JGME-D-19-00099.1

[25] Green M, Jones P, Thomas JX, Jr. Selection criteria for residency: results of a national program directors survey. Academic medicine : journal of the Association of American Medical Colleges 2009; 84(3): 362-7. https://doi.org/10.1097/ACM.0b013e3181970c6b

[26] Sawhill AJ, Dillon GF, Ripkey DR, Hawkins RE, Swanson DB. The impact of postgraduate training and timing on USMLE Step 3 performance. Academic medicine : journal of the Association of American Medical Colleges 2003; 78(10 Suppl): S10-2. https://doi.org/10.1097/00001888-200310001-00004

[27] Barajas-Ochoa A, Ramos-Remus C, Ramos-Gómez S, Barajas-Ochoa Z, Sánchez-González JM, Hernández-Ávila $M$, et al. Desempeño de las escuelas de medicina en México: resultados del Examen Nacional para Aspirantes a Residencias Médicas. Salud Publica de Mexico 2019; 61(4, jul-ago): 495-503. https://doi.org/10.21149/10042

[28] Freire JM, Infante A, de Aguiar AC, Carbajo P. An analysis of the medical specialty training system in Spain. Human resources for health 2015; $13: 42$. https://doi.org/10.1186/s12960-015-0038-y

[29] Baladrón J, Sánchez-Lasheras F, Villacampa T, RomeoLadrero JM, Jiménez-Fonseca $\mathrm{P}$, Curbelo J, et al. El examen MIR 2015 desde el punto de vista de la teoría de respuesta al ítem: Revista de la Fundación Educación Médica 2017; 20: 29-38.

https://doi.org/10.33588/fem.201.874 
[30] Angus SV, Williams CM, Stewart EA, Sweet M, Kisielewski M, Willett LL. Internal Medicine Residency Program Directors' Screening Practices and Perceptions About Recruitment Challenges. Academic medicine : journal of the Association of American Medical Colleges 2019. https://doi.org/10.1097/ACM.0000000000003086

[31] Gauer JL, Jackson JB. The association of USMLE Step 1 and Step 2 CK scores with residency match specialty and location. Med Educ Online 2017; 22(1): 1358579. https://doi.org/10.1080/10872981.2017.1358579

[32] Schrock JB, Kraeutler MJ, Dayton MR, McCarty EC. A Comparison of Matched and Unmatched Orthopaedic Surgery Residency Applicants from 2006 to 2014: Data from the National Resident Matching Program. J Bone Joint Surg Am 2017; 99(1): e1.

https://doi.org/10.2106/JBJS.16.00293

[33] DePasse JM, Palumbo MA, Eberson CP, Daniels $\mathrm{AH}$. Academic Characteristics of Orthopaedic Surgery Residency Applicants from 2007 to 2014. J Bone Joint Surg Am 2016; 98(9): 788-95.

https://doi.org/10.2106/JBJS.15.00222

[34] Manthey DE, Hartman ND, Newmyer A, Gunalda JC Hiestand BC, Askew KL, et al. Trends in NRMP Data from 2007-2014 for U.S. Seniors Matching into Emergency Medicine. West J Emerg Med 2017; 18(1): 105-9. https://doi.org/10.5811/westjem.2016.10.31237

Received on 15-04-2021

Accepted on 19-05-2021

Published on 25-05-2021

https://doi.org/10.6000/1929-6029.2021.10.05

(C) 2021 Mendoza-Aguilar et al.; Licensee Lifescience Global.

This is an open access article licensed under the terms of the Creative Commons Attribution Non-Commercial License (http://creativecommons.org/licenses/by-nc/3.0/) which permits unrestricted, non-commercial use, distribution and reproduction in any medium, provided the work is properly cited. 